\title{
Article
}

\section{Researching writing across the lifespan: The value of literacy studies for highlighting social and contextual aspects of change}

Tusting, Karin, Barton, David, Mcculloch, Sharon, Papen, Uta and Potts, Diane

Available at http://clok.uclan.ac.uk/26394/

Tusting, Karin, Barton, David, Mcculloch, Sharon ORCID: 0000-0003-4022-

2428, Papen, Uta and Potts, Diane (2018) Researching writing across the lifespan: The value of literacy studies for highlighting social and contextual aspects of change. Writing \& Pedagogy, 10 (3). pp. 401-422. ISSN 1756-5839

It is advisable to refer to the publisher's version if you intend to cite from the work. http://dx.doi.org/10.1558/wap.34589

For more information about UCLan's research in this area go to http://www.uclan.ac.uk/researchgroups/ and search for <name of research Group>.

For information about Research generally at UCLan please go to http://www.uclan.ac.uk/research/

All outputs in CLoK are protected by Intellectual Property Rights law, including Copyright law. Copyright, IPR and Moral Rights for the works on this site are retained by the individual authors and/or other copyright owners. Terms and conditions for use of this material are defined in the policies page. 


\section{Researching writing across the lifespan: the value of literacy studies for highlighting social and contextual aspects of change.}

Author 1, Author 2, Author 3, Author 4, Author 5

\section{Abstract}

This paper highlights the importance, when researching writing across the lifespan, of addressing a range of aspects of social context which change over time, particularly focusing on tools, values, relationships and identities. It illustrates this argument by drawing on a range of empirical studies exploring different aspects of writing in university settings, working with adults at a range of levels from Masters through doctoral study to academics' working lives, and reflects on the implications of this research for lifespan writing studies more generally. The projects drawn on include a study of multimodal feedback on postgraduate student writing and students' responses to this; a detailed study of academics' writing practices in the context of structural changes in Higher Education; and an interview study with $\mathrm{PhD}$ students participating in writing retreats, reflecting on their writing experiences.

Drawing on findings from this work, we argue that shifts in material, social and institutional dimensions of context have a significant impact on what individuals write and on the writing practices that they develop. We particularly highlight the role of changing tools for writing and values around writing, and the importance of transformations in identity and relationships. We argue that the tradition of literacy studies research, drawn on by all the projects described in this paper, provides the theoretical and methodological resources to approach such aspects of academic writing development across the lifespan, by adopting a holistic perspective on writing which locates writing as situated practice and thereby provides insight into these social and contextual influences.

Keywords

Literacy studies; academic writing; lifespan writing; multimodality; managerialism; identity; tools and technologies 


\section{Researching writing across the lifespan: the value of literacy studies for highlighting social and contextual aspects of change.}

\section{Introduction: Literacy studies in lifespan writing research}

This special issue focuses on developing a lifespan perspective in writing research. In order to do this effectively, we need to draw on appropriate theoretical and methodological resources to address the many issues which emerge around writing when looking through this longer lens. In this paper, we demonstrate how research which adopts the practice perspective of literacy studies can provide ways of addressing and thinking about, particularly, social and contextual factors which affect the development of individuals' writing over their lives, and we identify key factors within this which the work reported here highlights.

We locate our work within the particular perspective on literacy which has been called the 'New Literacy Studies' (Gee, 2000), which we will refer to as 'literacy studies' from hereon in. This is an approach first developed in the 1980's (Barton, 1994/2007, and see also Papen, 2005) which insists on seeing literacy as a social practice. The social practice model sets itself in explicit contrast to the skills model predominant then (and still, largely, now) in public opinion and educational policy. A skills perspective conceptualises literacy predominantly in terms of decontextualised, cognitive skills which individuals reach attain (or do not reachattain), largely by means of formal education, which can be assessed against external standards using standardised tests. In opposition to this, the literacy studies perspective conceptualises literacy firstly as something people do, as a set of practices people engage in as part of their lives.

While this perspective acknowledges that certain cognitive capabilities are necessary in order to engage in literacy practices, the social practice approach to literacy draws on sociocultural theories of cognition (e.g. Lave \& Wenger, 1988) to conceptualise how these capacities are learned and developed. A sociocultural model highlights the centrality of social interaction in the learning process. Learning, for an individual, takes place first in interaction with other people and with resources in the immediate environment, engaging in practices which are fundamentally social, cultural and material, before these learned practices become internalized. Cognitive skills are therefore not understood as being internal properties of the mind of an individual, but as arising from and rooted in the interaction between the individual 
and the cultural and material tools and resources, including other people, that are drawn on in using, and learning, these skills in practice. Literacy practices themselves can be seen as social and cultural resources, that is, as established ways of engaging in reading and writing which individuals learn through participating in them. At the same time, practices can be shaped and changed by individuals as they engage in them, exercising their agency within their own unique sets of circumstances., while the agency of individuats in their unique eircumstances can shape and change practices over time.

The idea that people engage in literacy practices for purposes which are meaningful to them in relation to other aspects of their lives implies that observing practices, while essential, is not enough. Research in literacy studies also engages with the individuals whose practices are being researched, to try to develop a good understanding of their own perspectives on these practices. This is often done through interview, but many other methods - including mapping (Mannion \& Ivanič, 2007), photography (Hodge \& Jones, 2001), collaborative digital storytelling (Hull, 2003) - have also been drawn on to facilitate development of this more emic understanding. This is a holistic perspective on people's literacy practices and their understandings of them in particular social contexts. All the studies reported here adopt this holistic empirical perspective, drawing on observation of and interviews about naturallyoccurring writing practices.

From a theoretical perspective, adopting an understanding of literacy practices as social and as ideological requires the researcher, in addition, to place these practices and their purposes and meanings in social and historical context. The inherently social nature of literacy implies that such practices are shaped by history and historical institutional forces, and that social and power relationships influence aspects such as who has access to which literacies and to which technologies, which literacy practices are considered superior and which inferior, which practices provide access to privileged locations in society and which do not, and so forth. Scholars in literacy studies draw on an eclectic range of social theoretical perspectives (e.g. Schatzki's philosophical ontology of social practice (Kaufhold, 2017), Bhabha's third space theory (Gutiérrez, 2008), Adam's social theory of timescapes (Burgess, 2010)) to bring together observations of practices with interpretation of the role of the broader social structural context in shaping them.

Research from this perspective has generated many insights which help us to understand the place of literacy in our social lives. For instance, a detailed study of literacy practices in one 
local area (Barton \& Hamilton, 1998/2012) identified the important role of literacy practices not taught in formal educational institutions in many aspects of people's lives, including the organization of family life, managing finances, leisure activities and to support people's 'ruling passions'. Importantly, much of this work has been with adults, which provides a different perspective on education from those researchers who focus on children and young people. While research on children's writing engages with writing both inside and outside school settings, adults rarely spend the majority of their time participating in formal education, and the importance of learning outside formal educational institutions in people's writing development across the lifespan has been a consistent finding across much of this work (Hamilton, 2006).

The studies discussed in this article demonstrate the value of these theoretical and methodological resources, developed in literacy studies, for studying how writers and writing develop across the lifespan. As Bazerman et al. (2017) acknowledge, a range of aspects of social context must be taken account of in developing lifespan writing research, including identity, multimodality, purpose, power and access, and skills and dispositions. In this paper, we draw on recent empirical research projects in literacy studies to show how this taking account of context has been done in practice, and to indicate the value of adopting a literacy studies perspective on research in writing development across the lifespan.

Each of the studies discussed here starts from the perspective of individuals to understand specific aspects of the development of their literacy practices over time, although the timeframes differ from the very immediate (responses to feedback, participation in a day retreat), through to the much longer timespans of working with changing technologies and within changing systems of evaluation. In different ways, each of them shows how adopting a practice perspective enables connections to be made between individuals' writing development over time and wider social and contextual changes.

[Author 2 $\underline{5}$ ] has researched postgraduates' responses to feedback in different modes, and reflects on how the changing technological affordances associated with new kinds of feedback tools are enabling the communication of values around writing in a new way and enabling different kinds of relationships between staff and students. [Author 32] describes how the tools and technologies available to academic writers have changed over time, and analyses the impact of these changes on their identity as writers and their writing practices. Drawing on data from the same project, [Author 4 $\underline{3}$ ] identifies the importance of the changing 
policy and strategy context on writers' evaluations of their own writing, and on how this changes their writing practices and their sense of who they are as writers. [Author 54] draws on a study working with doctoral students reflecting on their changing identities and

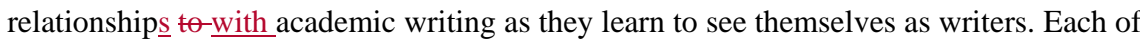
them is exploring changes in writing developments in individuals who are located in the academic world, at different points, from masters and graduate students through to professional academics. We show how developments in the writing practices they engage with can be connected to broader changes in tools, values, relationships and identities, and argue that attention to these connections between literacy practices and these particular aspects of social and contextual change would pay dividends for work addressing lifespan writing development well beyond the academic sphere.

\section{Changes in the nature of the text: multimodality, feedback, and power relations in} academic writing

The written text has long sat at the centre of educational work. It is how knowledge is offered, shared and evidenced, and is valued for its aesthetic as well as intellectual and pragmatic qualities. Its forms are multiple: it is short and long responses to examination questions, a child's self-authored alphabet book, and an undergraduate lab report in biochemistry. Its overt purpose shifts across educational contexts: it can be an exercise in replicating the thinking of an esteemed scholar, an act of self-expression, or evidence of one's ability to form a cogent argument. But regardless of the particulars of each instance of writing, the pedagogic text's larger purpose is to inculcate the writer into a system of socially sanctioned beliefs and values (Bernstein, 2000). Surfacing these values and interrogating how education functions to reify, reinforce or (in some cases) challenge the distributions of power and privilege that depend on their maintenance is a key endeavour of educational research. Any meaningful examination of writing across the lifespan must go beyond describing changes in pedagogic texts' functions and forms and account for the ways in which writing pedagogies position and reposition individuals within the larger social order.

However, it is no longer possible to understand the larger processes of education without engaging with the multimodality of texts and textual practices. Indeed, we can and should question the implications of continuing to privilege the written mode as a separate area of educational inquiry. Changes in the redistribution of meaning within and across modes are well-documented, and the shifts are now inescapable (Kress, 2010; Kress \& van Leeuwen, 
1996/2006). A wide range of new communication tools and technologies which enable this redistribution of meaning across modes are now readily available to both students and teachers. At a minimum, learners watch videos and tell digital stories, listen to podcasts and narrate audio slideshows, and engage with data visualization as readers and writers. Such superficial glosses of change, however, yield few insights into education's reg-ulatory functions. It is here where literacy studies' strengths come to the fore. Married with a multimodal lens, descriptions of what people are doing with literacy allow us to see the tensions created by new forms of everyday practice.

The most mundane of educational tasks, assessing and providing feedback, is illustrative. Feedback practices have been quietly transformed through use of annotation, screencasting and plagiarism software, which allow for new combinations of color, line, writing, audio and spatial resources for marking up texts. Each software is different, each individual's use of software is different again. Yet each negotiation of the pedagogic text is a potential transformation in institutional practice. Using a subset of data from a larger comparison of feedback practices, we have been exploring how one academic's use of iAnnotate $\AA_{\text {impacted }}$ postgraduate students' perceptions and feedback use (Author 5, under review). The eight individuals who participated in the larger project represented a cross-section of forty-three students who were offered three feedback options: a page of written feedback, in-text audio comments or a 20-minute face-to-face meeting. In addition to tools for highlighting, drawing, text annotation, etc., the audio annotation software offers an option for inserting short (less than one minute) audio clips into PDFs. The audio clips, which show as small sound icons, can be positioned next to the clause, sentence or paragraph being discussed. Together with the student's submitted assignment, the annotations, mark-up and audio create a multimodal ensemble distinct from paper-based or word-processed feedback. Given that students who received audio feedback reported consistently greater satisfaction, we sought to better understand why and how audio feedback produced the results it did.

Students' responses to audio feedback were overwhelmingly positive, but also revealed unsettling dynamics in teacher-student relations. On one level, audio feedback allowed students to critically assess the tutor's performance, suggesting a reduction in the perceived power differential between the two. Ting describes how the feedback functions in this regard:

Because that's why audio feedback is great. It's very detailed. For example, if she comments on this paragraph, you must read the whole paragraph. Or she 
mentions in the feedback about the connection between your this paragraph $[\mathrm{sic}]$ and the previous one, or connection with a later paragraph. It's about coherence or other stuff. Then you read again to see her reasons and to see whether she is correct or not.

It is important to see Ting's assessment for what it is. She is not evaluating audio feedback for ease of comprehension or use, but outlining how she assessed whether her tutor was correct. Because the feedback was detailed and its scope clear, she reread her assignment to check her tutor's reasoning. Lines and layout as well as comments, all of which were linked earlier in the interview to Ting's perceptions of detail and clarity, assisted her in identifying the scope of each comment. We suspect temporal relations also supported Ting: while students must reread their assignments in sequence with reading written feedback, audio allows students to simultaneously reread while listening. By attending to what Ting and other learners are doing with literacy, we see how multimodality contributes to potential shifts in control over the pedagogic text.

In contrast, some students' affective response to audio can mitigate against their adoption of a more critical perspective. Si's observations were typical:

It's her tone. Her emotions can influence you. Word choice too. Sometimes she is really excited, like 'Excellent!' and 'Si, this point is very, really blah blah.' It feels very sincere.

Such descriptions of audio's emotional impact stand in stark contrast to Ting's earlier comments. Si unquestioningly accepts the comments' emotional authenticity, and allows that her tutor's 'tone' and 'emotions' carry influence. Lan, commenting on audio's emotional appeal, stated, 'I feel she understands me' and 'It feels like she is on my side.' She went so far as to play her feedback to her parents, who did not speak English, because she wanted them 'to hear my teacher's voice.' Having her tutor on her side led Lan to more easily accept her corrections. However, there is less evidence of critical engagement with the feedback's content. The construed relationship was more intimate but no less hierarchal.

Without attention to the full scope of texts' multimodal features, we cannot give an account of the dynamics of changing communication practices across the lifespan, as new tools and technologies become available and enable new kinds of engagements with texts. Without attention to what people are doing with texts, our understanding of those dynamics is 
curtailed. Although there is some research exploring student and teacher experiences (e.g. Fawcett \& Oldfield, 2016; Mann, 2015), much of the work on feedback focuses specifically on feedback type and its impact on student writing, and is assessed using quasi-experimental designs that employ pre- and post-tests or detailed analysis of the feedback and writing (e.g. Elola \& Oskoz, 2016; Ene \& Upton, 2014; Ice et al., 2010). While such work contributes to knowledge in its own right, it fails to capture how individuals are positioned and position themselves in these social processes. Our work on feedback raises larger questions about the lack of attention to oral texts, to the impact of prosody on individuals' critical evaluation of information, and to the privileged practices of the rhetor in contemporary communication. But without attention to practice and to texts' multimodality, such questions may not be raised.

In terms of lifespan writing development, we see here how such tools and technologies can enable these students to engage with and reflect on evaluations of their writing in new and different ways. The relatively new tool of iAnnotate, by allowing audio (and other) feedback to be provided on students' assignments, can enable changes in the relationships between students and teachers, both potentially shifting the hierarchical relationship usually associated with assessment in favour of the student by facilitating a more specific and con-sidered evaluation of the feedback received, and introducing a more affective aspect to the pedagogic relationship by reading emotional responses into the prosody of the audio evaluation.

\section{Changes in the tools and technologies available for writing}

Changes in the tools available for providing feedback on students' work are just one example of a radical expansion in the tools and resources drawn on in literate activity in the last twenty to thirty years, with a shift to digital forms of communication in almost every social sphere transforming literacy practices across adult lifespans. The higher education sector was one of the leaders in this field. The increasing multimodality of the pedagogic text discussed above represents one small aspect of the many developments in the tools, platforms and resources available which are changing what it means to do academic writing and therefore, to a degree, what it means to be an academic.

These tools and technologies are of many kinds. New sets of resources are provided by the institution in the work place, such as virtual learning environments which support many of the different aspects of teaching and learning, facilitating distance and blended learning and 
collaboration. Publishing articles, applying for grants and sending abstracts to conferences rely on commercial platforms such as online submission systems which bring together processes of submitting, reviewing, revising and accepting papers. Those providing student support, courses for academics and library services also find their involvement in technology mediated practices changing, with libraries providing digital resources, putting on graduate courses in research methods and maintaining reading lists online. File sharing software, video-conferencing and other tools provide new affordances for collaborative work, from two colleagues on the same corridor sharing a document to a multi-sited international team project. Smartphones and portable devices along with associated software or apps for everyday life get used in academic life, blurring the division between home and work, for instance where people first use Skype to keep in touch with distant family members, then cautiously at first, becoming more routine later - in the workplace.

Such transformations in technological tools and resources have been explored in another project rooted in a literacy studies approach, $\subseteq$ The Dynamics of Knowledge Creation:

Academics writing in the contemporary university workplace-. The study was funded by the UK Economic and Social Research Council and has been examining contemporary changes in academics' writing practices. The project adopted a literacy studies perspective, working closely with individuals to understand the literacy practices of working academics.

This project worked with academics at three universities in England focussing on three disciplines, mathematics, history and marketing. These disciplines were chosen to be distinctly different from each other. Data was collected in 2015-2017 and the study built upon an earlier study which collected data in 2009 (see Author 2 et al, 2013). The study was multimethod and used a range of different sorts of interviews with academics including walkaround interviews, techno-biographic interviews and day-in-the-life interviews. There were also live recordings of academics' writing processes and interviews with other colleagues. The academics ranged from early career researchers through to senior professors. Overall, 70 participants were interviewed, and the work reported here draws mainly on the technobiographic interviews (Barton \& Lee, 2013). Transcribed interviews were imported into ATLAS.ti qualitative data analysis software and coded, following a provisional coding scheme based on the research questions of the project, enhanced by further ideas and concepts which emerged during the analysis of the data. The analysis aims firstly to make sense of individual academics and their writing lives, from their own point of view, focusing 
on individual ways of acting and dealing with change and tensions in their lives. The second important step in the analyses consisted of weaving common themes across individual cases, using both prior themes and emergent ones.

As discussed in the introduction, a literacy studies perspective entails among other things engaging with the emic perspectives of the individuals in question. We learned, for instance, that what people meant by 'writing' in their academic working life was very fluid. Sometimes it included emails, at other times writing was contrasted with emails. They also distinguished between the administrative work they were required to do and 'real work' or 'serious writing', usually signalling by this writing up academic research for publication - an issue that relates to the institutional value associated with particular types of writing, discussed further below.

People reported drawing on a wide range of digital tools and technologies in their writing. The tools that were used and how they were used were continually changing. Common practices included writing papers in Word, using Skype for distant communication and using Dropbox for storing and sharing files. Across disciplines, people drew upon different tools. Mathematicians wrote using Word along with LaTeX, a maths text editor, while still using chalk and blackboards in teaching spaces. Historians used digital tools to record archival material, with one finding that digital cameras revolutionised these processes. Many people still liked to write by hand for specific tasks and a few used index cards. Hand written notes were sometimes the first step in writing an academic paper, but increasingly people talked of using PowerPoint slides as the starting point for an article. While academics had control over some aspects of writing, such as the tools used for drafting writing, in many areas there is strict control over the software which has to be used such as when registering to go to a conference, submitting a paper to a journal, reviewing journal articles, or registering to attend a talk. Understanding such changes and continuities in the use of different tools over time provides one way into developing a lifespan perspective on writing development.

The tools and technologies available to people shape other aspects of their writing choices. When asked about the context of their writing the academics reported that they worked in different places. Some never did serious writing in their workplace offices. Others needed a particular place for writing, often wanting somewhere they would not be disturbed. They often worked in different places in order to maintain boundaries between different sorts of writing. On the other hand, some reported doing all sorts of writing in the same place, saying 
that all writing, including emails, administration and lecture-writing were done at home. Such material decisions about where to work were strongly influenced by the tools and technologies available. Technology enables working on emails, marking, writing articles, in different places, in cafes, airports, the beach, taking advantage of global systems of free or cheap internet provision, but at the same time making it very difficult to find a space away from work responsibilities and hard to maintain a separation between personal and professional identity.

Mapping the genres of writing people engaged in proved a fruitful source of insight into how changes in tools and resources affected their writing practices over time. In the interviews people named a wide range of sorts of writing which they participated in, mentioning 91 different and distinct genres, including research genres (journal articles, monographs), teaching genres (feedback, lecture slides), and administrative genres (handbooks, reports). The ways in which many of these texts were produced have changed, partly as a consequence of technological changes. Some of the digital technologies used, such as Powerpoint for teaching preparation and conference papers, or email for everything, are well-established. Others, such as online submission systems, were new or changed regularly.

Returning to the specific example of the genre of feedback on students' work, most academics we spoke to were now expected to provide feedback to students online using a virtual learning environment and sometimes using grading programs, and this was a relatively recent change. These changes then lead to new practices, implicating changes in relationships both between teacher and student, as discussed above, and between colleagues, administrators and managers. Whereas feedback used to be a personal communication between teacher and student, online systems enable greater overview of the marking process. Other actors in these practices, such as administrators and course leaders, may have access to the feedback and hence the capacity to evaluate and critique it. (See Authors 2 and 3, under review.)

The affordances of the Internet further diversified the range of genres of writing academics in our study engaged in over time. Social media hold the possibility of new forms of writing, addressing new audiences such as prospective new students, particular groups of academics, or non-academic audiences. This has led to new forms of writing being available online, such as drafts of articles, versions written for lay people, or conscious publicity for new publications. Academics are increasingly creating and maintaining online identities. The majority of academics participating in the project were now required to maintain an 
institutional profile page on the university's website, and many had non-institutional ones too, through academic networking sites such as ResearchGate and Academia.edu. Some had begun contributing to departmental, disciplinary or personal blogs, or using Twitter or Facebook professionally.- Like their use of different software platforms discussed above, often their activity on social media started in everyday life and shifted to professional use. Although at first individual Twitter accounts and blogs were largely ignored by the universities, more recently they were becoming seen as positive and an essential component of a university's 'digital strategy'.

While the new genres of writing associated with social media are made possible by technology, they do not entail just 'new technical stuff', but also, as Lankshear and Knobel (2011) argue, 'new ethos stuff'. Specifically, they carry with them values that sit uneasily with those of traditional scholarly writing practices centred around peer-reviewed publications. In digital spaces, expertise tends to be seen as distributed rather than closely guarded by gatekeepers, as it is with more traditional peer-reviewed publication venues. Knowledge creation is viewed as a collaborative and participatory endeavour, and users of many online platforms are as much producers as consumers of knowledge. Some academics in our study embraced these values and actively used social media to engage others in scholarly conversations, as illustrated in this comment by Rebecca, a historian:

I attempted to set up a blog when I was writing the last monograph because I wanted to try and rope in as many people to a discussion about it [as possible].

Rebecca's efforts to use the participatory potential of blogs fits with notions of literacy as a social practice as discussed above, but also highlights that this form of knowledge creation might be seen as less valuable than the monograph it was intended to inform and promote.

Not all academics used social media, however, partly because they felt uncomfortable with the element of reputation management, or, arguably, marketing, it involves. Gareth, a professor of mathematics, said, in response to a question about whether he used Twitter:

I seriously don't get it at a personal level and I think I've rather let my outputs speak for themselves rather than anything else. 
Gareth's comment refers less to his views about technology per se, and more to his feelings about a culture in which an academic's role extends to marketing eneself themselves as a commodity.

This discussion shows how writing across academics' professional lifespans has been transformed by a very wide range of new communicative tools and technologies in recent years, requiring ongoing learning to master the new genres and practices associated with them. In engaging with the possibilities of new communications technologies, academics can establish new kinds of public professional identities for themselves through writing, but distinctions between professional and personal identities can become increasingly blurred. The writing associated with new social media tools in particular can enable new kinds of relationships with audiences, but can also challenge established systems of valuing academic work.

\section{Changes in managerial practices and in how writing is valued}

A literacy studies perspective encourages us to locate changes in individuals' professional writing practices across their lifespan in a broader social and institutional perspective. The change and expansion in the use of technological tools and resources described above is closely coupled with, and facilitates, other social and managerial changes to which higher education in England has been subject to-over the last 20 years or so. The social and political understanding of the purpose of the university in society has changed quite fundamentally. University education has changed from being the privilege of a small, elite group (less than $10 \%$ of young people between 18-30 attended university in England in the 1980s) to being seen as essential to the production of a skilled workforce for a contemporary knowledgebased economy, with nearly $50 \%$ of young people now attending (the target of $50 \%$ having first been adopted in the 1997 Labour Party manifesto), (Wolf, 2004)). This rise in student numbers has been accompanied by the introduction, and then the rapid raising, of student fees. Relationships between students and academics have changed as a result, with students (reasonably enough, given the investment they are making and the level of debt building up as a result) expecting high levels of individual attention and rapid, if not instant, responses from academic staff, facilitated by the ubiquitous use of email in the sector.

Universities, becoming more and more like businesses in the way they operate, are looking to expand and diversify through internationalisation, both by attracting overseas students and by 
extending their distance and international campus provision. The wider policies of internationalization and massification are supported and made possible by virtual learning environments which support distance teaching and blended learning and collaboration.

New tools and platforms also facilitate the changes in university management which have been termed the 'audit culture' (Strathern, 2000). Changes in the way UK higher education is run, particularly the adoption of a more managerialist approach (Deem, Hillyard, \& Reed, 2007), means that academics often have to spend time doing writing aimed at demonstrating accountability. For example, the introduction of quality assurance mechanisms has meant that standardised module descriptions and learning outcomes are often required to be written, and these can be a source of frustration, as demonstrated by one professor of marketing, Diane's, comments (from the same project discussed above):

It never ends. The handbook, the bloody student handbook, God. You have to repeat everything endlessly, so with the programme I had to write pages and pages of stuff to justify what the aims of the course were, of this new master's programme, and then you have to justify it and then you have to justify that there's a market there and demonstrate evidence for the market.

Although these forms of writing may not fall within what many would consider the core academic business of knowledge creation, they have to be learned, they take up precious time and energy, and they contribute to knowledge of a different type from the traditional scholarly contribution. Justifying the existence of courses in relation to marketability helps to construct the university as an institution driven by market principles.

Another force which now plays a key role in shaping academics' writing practices came arises from the effects of research evaluation systems, strategic plans made by institutions and departments to maximise their chances of success in an increasingly competitive environment, particularly in university league tables and in the Research Excellence Framework, a national evaluation of research quality. These strategies tend to privilege peerreviewed journal articles, particularly in high-impact journals. Other forms of knowledge creation are less highly valued because they take longer to produce, generate fewer citations or do not appear in prestigious high-ranking journals, that the prestige of which can be drawn enused in evaluation systems as a proxy for the quality of the research itself. Our participants 
told us that genres such as trade journals, monographs and textbooks were perceived as being under threat or de-prioritised. As Rose, the head of a marketing department, put it:

Our currency is really journal articles. For me, but I don't think it’s just me, writing a textbook is like a part-time job. That's, 'Squeeze it in in your own time.'

We also found that academics working in more teaching-intensive universities, without a strong research tradition, where the teaching load was typically higher, struggled to find time to do research. Some, particularly early career academics, reported that- although the emphasis on research was low in their current institution, they tried to exceed the targets they were set for publishing there because they aspired to move to a more research-intensive university, and. They knew that in order to be employable in that setting, they would needed a strong track record of publishing journal articles.

These findings illustrate the importance of acknowledging both the importance of academics' writing practices in shaping their own identity and career trajectory over long periods of time, and the need to understand such practices within a wider social and historical context. Our individual choices about what to write and where to publish interact with broader societal forces, including those that position certain types of knowledge creation as more valuable than others. The key tenets of literacy studies that literacy practices are historically situated, institutionally situated and enmeshed in power relationships help us to see how such changes play out in the writing development across the lifespan both of individuals and of whole professions.

\section{Changes in the autobiographical self: identity, self-perception and relationship to} literacy

Conceiving To conceive of writing as a practice that is centrally shaped by the social context within which writing takes place, and by the writer's personal history and experiences of literacy throughout their lifespan ${ }_{2}$ necessarily entails a focus on identity. Research in literacy studies has frequently emphasised the importance of the relationship between literacy and identity (e.g. Ivanič, 1998; Lee \& Barton, 2011; Rowsell \& Pahl, 2007). Researching writing across the lifespan entails-requires understanding how changing writing practices are intrinsically part of who people are and who they are becoming, an ongoing process which continues throughout people's lives. 
This relationship between writing and identity is highlighted at times of life transition. When embarking on a $\mathrm{PhD}$, for instance, students bring with them experiences of writing in different contexts and during different periods of their lives (Ivanič, 1998). In a study of PhD students' experiences of writing their thesis, students were asked whether they perceived themselves as writers. This question was part of in-depth conversations with 19 students, all of whom had taken part in one or more writing retreats organized by their Faculty between 2014 and 2016. The aim of these interviews was to understand the role of the retreats in relation to the students' experiences of writing their $\mathrm{PhD}$. To explore this, we enquired not only into their views of the writing retreat, but asked questions about their prior experiences as writers, from childhood, and school to university and work. The responses to this question shared below have been chosen as they illustrate effectively a central theme that emerged from all of the interviews, that is, the importance of their perceptions of their own identity in writing at doctoral level.

Sara: 'I don't really see myself as a writer (Laugh), I see I'm doing writing'.

Adam: ' $\ldots$. all of this is to say that I perceive myself as a bad writer. Not necessarily that my content is bad.....I think I'm terrible at spelling and grammar.'

Adam (later in the same interview): 'I don't think of myself as somebody who does an incredible amount of writing...So I would say reluctant, somewhere between bad and reluctant.'

Gail: 'You're standing behind of what you're saying, you as a person with values and beliefs in your own academic work and therefore to turn something out that isn't fully thought through has quite different implications to you know something that's less serious'.

Sara, Gail and Adam were all in the writing stage of their $\mathrm{PhD}$ and all three of them, while having ambiguous feelings about their writing, were producing work that was well received by their supervisors. While the PhD imposed new demands on them - Gail for example explained that the complexity of the ideas she was dealing with was not comparable to MA level work - the key to understanding their experience of the PhD generally and the retreat more specifically lies in particular in the question of their identities as academic writers. Prior and current experiences of writing played an important role in the students' perceptions of themselves as academic writers. 
Many of the students interviewed had prior careers as writers in professional or personal contexts. Michelle, for example, had been a manager in higher education, confidently dealing with many genre specific writing demands. Starting the $\mathrm{PhD}$, her first experiences were of swimming 'in a soup of alien language', very different from what she was used to. Her previously confident evaluation of herself as a writer was shattered. Adam, on the other hand, had always been ambiguous about valuing himself as a writer. In the interview, he talked repeatedly about being bad at spelling and grammar. His mother, who he used to 'submit' (his word) all his writing to until her recent death, 'edited' all his work and 'formed [him] as a writer'.

What the students told us resonated specifically with what Ivanič (1998: 32) calls the autobiographical self: 'the identity which people bring with them to any act of writing, shaped as it is by their prior social and discoursal history'. Our interviews showed that a student's autobiographical self, as Ivanič suggests, changes across their lifespan. These changes emerge partly as the positions available to the writer in their social environment they are part of-change. Inherent in the experience of doing a $\mathrm{PhD}$ is the liminal position doctoral students occupy: they are both researcher and student. All their writing is scrutinized by more powerful academic writers. The ultimate arbiter of a PhD student's ability to move from their aspirational identity as an academics (Hall \& Burns, 2009) to achieving an acknowledged position as a member of the field is the examination of a piece of text: the thesis. Writing retreats were a positive event in the journey towards that position. They offered a space where $\mathrm{PhD}$ students were not just writing but where, as Daniel, another participant said, they were able to feel they were 'legitimate' writers.

These experiences show that literacy is never acquired once and for all. To capture a person's development as a writer, we can draw here on the idea of a person's relationship with literacy (rapport à l'écrit, Besse,1995) which changes over time and across the social contexts we engage in. Specific skills, such as a doctoral student's ability to handle discipline specific terminology and theory, are part of the relationship with literacy, too, as Besse has suggested. But at the heart of a person's relationship with literacy is their changing sense of self as writer, with different experiences feeding into that ongoing perception of oneself as a good or bad writer. While individual writing events can produce 'shifts' (Grant, 2006) in that relationship, there are also enduring influences, as demonstrated in Adam's comments. That writing is a matter of identity is eloquently expressed in Gail's words. Her comments on the 
kind of writing required for a $\mathrm{PhD}_{\text {a }}$ also illustrate that at this level writing is required to be 'knowledge-creating', not only 'knowledge-recording' (Ferguson, 2009: 294), and is thus about much more than the ability to formulate sentences and produce paragraphs. The creation of new knowledge is a requirement for a successful thesis, but it also becomes part of the writer's own identity - as Gail says, the person is 'standing behind' the writing and the claims to knowledge which are being made.

Finally, our interviews also revealed that engagement with literacy practices has a strong affective dimension. The students in our study frequently revealed strong emotions about their writing, from 'hating it all' when having managed after weeks of struggle to produce a draft chapter to experiencing 'pleasure' when seeing themselves and others writing at the retreat. Thesis writing, Aitchison, Catterall, Ross, and Burgin (2012: 438) suggest, is 'emotional work'. For Daniel and others it was the pleasure of writing during the retreat that produced the feeling of being a legitimate academic. This study shows how the affective dimension of writing is closely linked with the writer's identity. The need to develop the desire and persistence required to write such a long text and the ability to move past the blank screen or page were issues frequently mentioned in the interviews. The emic perspective entailed by a literacy studies perspective allowed us to explore such issues of affect and identity in depth, which were crucial to these students' development as writers across their lifespans.

\section{Conclusion}

In this paper, we have drawn on a range of different projects which adopt a literacy studies perspective to demonstrate the value of this approach in researching writing development across the lifespan. We have argued that approaching literacy as a social practice enables researchers to address the role of a range of social and contextual influences in the development of writing. We have focused particularly on writing development through adulthood in academic life, drawing on studies which have explored aspects of writing at different points on the academic lifespan - MA students, PhD students, and professional academics. This has highlighted how changes in systems of value and in the tools and technologies available and systems of value-affect lifespan writing development, and how this connects to changes in relationships with others and to evolving conceptions of self. The paper shows how changing writing across the lifespan cannot be reduced simply to acquiring 
new genres, skills or even repertoires of practices. It is fundamentally tied up with social, relational and identity issues.

Through addressing literacy as social practice, our work supports the importance of placing situated practices at the centre of any conceptualisation of reading and writing. Addressing the local realities of individuals' experiences provides insights into their learning processes, how they adapt to new circumstances and how they incorporate new tools and technologies into their practices - often through processes of informal learning, working beside more experienced colleagues, or transferring practices from everyday life into professional domains. Each of these examples underlines the importance of values, identity and relationships with other people in the ongoing development of one's relationship with writing.

We argue, too, for attention to be paid to broader questions of history, institutional dynamics and power relationships in addressing literacy across the lifespan. This is particularly important at times of great ehangestransformations, and literacy studies provides a way of locating changes in individuals' writing practices in relation to broader social changes. We have shown, for instance, how addressing the relatively new capacity to produce feedback on pedagogic texts multimodally provides insights not only into the changing nature of the text itself, but also into how these changes can position staff and students in new kinds of relationships to one another, reshaping academic practice and with thisit, challenging some of the established hierarchies of academic teaching and learning. Investigation of changing tools and technologies in the academic workplace provides insights into how academics' workplace writing practices are changing and expanding. Tools and technologies enable certain new kinds of practices and constrain others. Analysing how academics are positioned and evaluated by managerial practices shows how their changing writing practices are part of much broader social changes in the nature of the university. $\mathrm{PhD}$ students cautiously negotiate and question their new, fragile identities as academic writers, in relation to a powerful system over which they have little influence or control. By engaging in writing practices-together, they start to see themselves as legitimate writers. This-which enables them

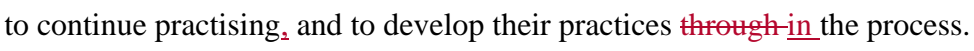

This broader perspective reinforces the fundamentally ideological nature of literacy (Street 1984) outlined above in showing how the way_tools, values, relationships and identities shape writing development through the academic lifespan. While all of the examples we have 
drawn on have been situated in academic settings, we would argue that paying close empirical attention to changing tools, values, relationships and identities from a broader literacy studies perspective can provide valuable insights in understanding the relationship between the social context and individual writing development in many other settings where literacy practices change across the lifespan.

In pedagogical settings, where the aim is to intervene in existing literacy practices and to support them to change and develop in a particular direction, reflection on a) the interaction between the-tools to be used in the teaching and learning, $\underline{\text { b) }}$ the values which are drawn on in the teaching and those which shape the setting, $\underline{\mathrm{c})}$ the relationships constructed between teachers and learners and between learners themselves, and d) the identity possibilities open to learners engaging in writing practices could frame useful reflection on the design of pedagogical interaction.

In the emerging field of lifespan literacies research, this work underlines the arguments for seeing literacy development as part of a bigger picture. Writing development becomes understood as something which continues throughout people's lives. The tools available to people change over time; they are placed in different kinds of relationships and develop new identities; values and purposes for literacy change and develop. Researching lifespan writing development is therefore not simply a study of how skills, genres or repertoires change over time.; it It is a study of who people become and how they are becoming in a bigger social context, explored through the lens of changing writing practices. 
Aitchison, C., Catterall, J., Ross, P. and Burgin, S. (2012) 'Tough love and tears': Learning doctoral writing in the sciences. Higher Education Research \& Development vol. 31, no. 4: 435-447.

Barton, D. (1994/2007) Literacy: An Introduction to the Ecology of Written Language, London and New York: Routledge.

Barton, D. and Hamilton, M. (1998/2012) Local Literacies. London and New York:

Routledge.

Barton, D. and Hamilton, M. (2000) Literacy practices. In D. Barton, M. Hamilton and R. Ivanič (eds.) Situated Literacies: Reading and Writing in Context, 7-15. London and New York: Routledge.

Barton, D. and Lee, C. (2013) Language Online: Investigating Digital Texts and Practices. London and New York: Routledge.

Barton, D. and Papen, U. (2010) The Anthropology of Writing: Understanding Textually Mediated Worlds. London: Continuum.

Author 2 et al. 2013.

Authors 2 and 3, Xxunder review.

Bazerman, C., Applebee, V. W, Berninger, D., Brandt, S. G., Matsuda, P. K., Murphy, S., Wells, D. W. and Schleppergrell, M. (2017) Taking the long view on writing development. Research in the Teaching of English vol. 51, no. 3: 351-360.

Bernstein, B. (2000) Pedagogy, Symbolic Control and Identity: Theory, Research, Critique. Lanham, MD: Rowman \& Littlefield.

Besse, J.-M. (1995) L'écrit, l'école et l'illettrisme. Paris, France: Éditions Magnard.

Burgess, A. (2010) Doing time: an exploration of timescapes in literacy learning and research. Language and Education vol. 24, no. 5: 353-365. 
Deem, R., Hillyard, S. and Reed, M. (2007) Knowledge, Higher Education, and the New Managerialism: The Changing Management of UK Universities. Oxford: Oxford University Press.

Elola, I., and Oskoz, A. (2016) Supporting second language writing using multimodal feedback. Foreign Language Annals vol. 49, no. 1: 58-74.

Ene, E. \& Upton, T. (2014) Learner uptake of teacher electronic feedback in ESL composition. System vol. 46, 80-95.

Fawcett, H., \& Oldfield, J. (2016) Investigating expectations and experiences of audio and written assignment feedback in first-year undergraduate students. Teaching in Higher Education vol. 21, no. 1: 79-93.

Ferguson, T. (2009) The 'write' skills and more: a thesis writing group for doctoral students. Journal of Geography in Higher Education vol. 33, no. 2: 285-297.

Gee, J. (2000) The New Literacy Studies: from socially situated to the work of the social. In D. Barton, M. Hamilton and R. Ivanič (eds.) Situated Literacies: Reading and Writing in Context 180-196. London and New York: Routledge.

Grant, B. (2006) Writing in the company of other women: exceeding the boundaries. Studies in Higher Education vol. 31, no. 4: 483-495.

Gutiérrez, K. D. (2008) Developing a sociocritical literacy in the third space. Reading Research Quarterly vol. 43, no. 2: 148-164.

Hall, L. and Burns, L. (2009) Identity development and mentoring in doctoral education. Harvard Educational Review vol. 79, no. 1: 49-70.

Hamilton, M. (2006) Just do it: literacies, everyday learning and the irrelevance of pedagogy. Studies in the Education of Adults vol. 38, no. 2: 125-140.

Heath, S. B. (1983) Ways with Words: Language, Life and Work in Communities and Classrooms. Cambridge: Cambridge University Press.

Hodge, R. and Jones, K. (2001) Photography in collaborative research on multilingual literacy practices: images and understanding of researcher and researched. In M. Martin- 
Jones and K. E. Jones (eds.) Multilingual Literacies: Reading and Writing Different Worlds 299-318. Amsterdam: John Benjamins.

Hull, G. A. (2003) At last: youth culture and digital media: new literacies for new times. Research in the Teaching of English vol. 38, no. 2: 229-233.

Ice, P., Swan, K., Diaz, S., Kupczynski, L., \& Swan Dagen, A. (2010) An analysis of students' perceptions of the value and efficacy of instructors' auditory and text-based feedback modalities across multiple conceptual levels. Journal of Educational Computing Research vol. 43, no. 1: 113-134.

Ivanič, R. (1998) Writing and Identity: The Discoursal Construction of Identity in Academic Writing. Amsterdam: John Benjamins.

Kaufhold, K. (2017) Tracing interacting literacy practices in master's dissertation writing. London Review of Education vol. 15, no. 1: 73-84.

Kress, G. (2010) Multimodality. New York: Routledge.

Kress, G. and van Leeuwen, T. (1996/2006) Reading Images: The Grammar of Visual Design. New York: Routledge.

Lankshear, C. and Knobel, M. (2011) New Literacies: Everyday Practices and Social Learning (3rd edition). Maidenhead: Open University Press and McGraw-Hill.

Lave, J. and Wenger, E. (1988) Situated Learning: Legitimate Peripheral Participation, Cambridge: Cambridge University Press.

Lee, C. K. M. and Barton, D. (2011) Constructing glocal identities through multilingual writing practices on Flickr.com ®. International Multilingual Research Journal vol. 5, no. 1: 39-59.

Mann, S. (2015) Using screen capture software to improve the value of feedback on academic assignments in teacher education. In T. Farrell (Ed.) International Perspectives on English Language Teacher Education 160-180. London: Palgrave Macmillan UK.

Mannion, G. and Ivanič, R, (2007) Mapping literacy practices: theory, methodology, methods.-_nternational Journal of Qualitative Studies in Education, vol. 20, no.1: 15-30. 
Rowsell, J. and Pahl, K. (2007) Sedimented identities in texts: instances of practice. Reading Research Quarterly, vol. 42, no. 3: 388-404.

Papen, U. (2005) Adult Literacy as Social Practice: More than Skills. London and New York: Routledge.

Author 5, under review.

Authoret al., 2015

Street, B. (1984) Literacy in Theory and Practice. Cambridge: Cambridge University Press.

Wolf, A. (2004) Education and economic performance: simplistic theories and their policy consequences. Oxford Review of Economic Policy vol. 20, no. 2: 315-333. 